\title{
THE VALUE AND ACCOUNTING PREMIUM FOR SOUTH AFRICAN-LISTED SHARES
}

\author{
Jürgen Ernstberger \\ Georg-August-University Goettingen, Germany \\ ernstberger@wiwi.uni-goettingen.de \\ Christian Heinze* \\ University of Regensburg, Germany \\ christian.heinze@stud.uni-regensburg.de \\ Oliver Vogler \\ University of Regensburg, Germany \\ mail@olivervogler.de
}

August 2008

\begin{abstract}
In the last decade, empirical research has found strong evidence that value stocks provide higher returns than growth stocks (value premium). Firms with a high ratio of book value of equity to market value of equity are regarded as value stocks; a low ratio identifies growth stocks. Most research is tailored to the market in the United States of America. Only a few studies consider country-specific distinctions. This research analyses the value premium for the South African market and compares its magnitude to the findings for the US market. Moreover, the effects of the introduction of International Financial Reporting Standards (IFRS) for companies listed at the JSE Limited are examined. The adoption of IFRS is used to demonstrate that investors award an accounting premium for voluntary compliance with this new accounting standard.
\end{abstract}

Keywords:

Value premium, accounting premium, South Africa, asset pricing, Fama-French model, multifactor model 


\section{INTRODUCTION}

This research examines two patterns in stock returns for firms listed at the JSE Limited (previously the Johannesburg Securities Exchange): the value premium and the accounting premium. Firms with a high ratio of book value of equity to market value of equity are regarded as value stocks; a low ratio identifies growth stocks. The excess return of value stocks over growth stocks is referred to as a value premium. An accounting premium is said to exist if investors reward voluntary compliance with International Financial Reporting Standards (IFRS) prior to its becoming compulsory in 2005 with a lower expected return.

Research in empirical finance, initiated by the pioneering work by Fama and French (1992, 1993), has documented the existence of a value premium in a variety of capital markets. In this strand of literature it is often claimed that the value premium exists exclusively among small stocks. If this were the case, the majority of investors' wealth would be unaffected. This critique is taken into account by explicitly investigating the distribution of the value premium for different company sizes. Moreover, the introduction of mandatory IFRS accounting in 2005 for firms listed at the JSE Limited is used to investigate the existence of an accounting premium. This premium is examined within different size classes as well as for value stocks and growth stocks separately. Furthermore, the article analyses whether Capital Asset Pricing Model (CAPM) captures the investigated patterns. Finally, whether or not the premiums qualify as risk factors is investigated in a multifactor model.

The findings suggest the existence of a value premium of about $1.5 \%$ to $2 \%$ both in the pooled sample as well as in subsamples of small and large stocks. No indication of differences in the value premium between the two different size classes is found. Moreover, an accounting premium of similar size is identified. A closer look reveals, however, that the existence of the accounting premium is limited to small stocks and value stocks, while large stocks and growth stocks do not share this pattern. Furthermore, the CAPM does not capture the value premium. Both the value property and the accounting standard in use qualify as priced risk factors. Thus, the contribution to the literature is twofold. First, most recent evidence on the value premium is provided for a market that has been relatively disregarded so far, i.e., South Africa, and shows that this effect does not depend on the size of the stocks. Second, the existence of an accounting premium for voluntary compliance with an internationally standardised accounting standard is documented and it is shown that both the value property and the accounting standard in use are priced risk factors in the South African market.

The remainder of this paper proceeds as follows. Section 2 describes the background of the study and gives an overview of prior research with a similar focus. After providing details about the sample and the portfolio construction (section 3 ), the research methodology is described in section 4 . Section 5 discusses the empirical results and section 6 concludes with a summary and a final comment.

\section{BACKGROUND AND PRIOR RESEARCH}

Asset pricing is an important field of research in finance. In addition to the CAPM, several multifactor models have been developed for explaining stock returns. Following the seminal papers of Fama and French $(1992,1993)$, several other studies have documented the failure of 
the CAPM to adequately explain asset returns. These studies usually refer to anomalies, e.g., size effect or momentum effect, which are not explained by the CAPM. However, most of these studies are conducted for the US market or other developed economies. Only a few studies investigate emerging markets like South Africa, which exhibits the largest market capitalisation in Africa (African Securities Exchanges Association, 2008) and the 19th largest worldwide (World Federation of Exchanges, 2008). Trade was established in 1887; today the JSE Limited lists more than 450 firms on its main board (JSE Limited, 2008).

Since 2005 , firms listed at the JSE have been required to comply with IFRS. Up to that year firms were free to choose between IFRS and South African Statements of Generally Accepted Accounting Practices (SA GAAP). Until 2005 the two accounting regimes were harmonised (JSE Limited, 2004). Thus, only small differences remain between them. This transition allows for an examination of whether investors reward the higher degree of international comparability when applying IFRS with lower return expectations.

Prior research on stock returns at the JSE includes that of Van Rensburg and Robertson (2003). This research found that the cross-section of stock returns is captured by similar variables as on the US market: size, dividend yield, earnings-to-price, and book-to-market. The results of this study are largely in line with the results of prior papers by Page and Palmer (1993) and Van Rensburg (2001).

The contribution of this research lies in the specific consideration of the effect of book-tomarket (value premium) and the accounting standard in use (accounting premium) on stock returns during the years following 2000.

\section{DATA AND PORTFOLIO CONSTRUCTION}

The investigation is based on a panel of 185 firms listed at the JSE from July 1998 to June 2007 (108 months). Finance and insurance firms (SIC codes 6000 to 6999) are excluded because they are fundamentally different from non-financial firms in book value of equity. The remaining 159 firms are investigated in the following analyses. These firms are used to form six portfolios on market value (market capitalisation, i.e. shares outstanding times share price) and book-tomarket - that is, the ratio of book value of equity to market value of equity.

The portfolio design is identical to that of Fama and French (1993). Portfolio construction proceeds as follows. In June 1998 firms reporting a positive book value at the end of 1997 and whose returns are known for every month up to June 1999 are considered for portfolio assignment. In line with Fama and French (1992), book value is defined as book value of stockholders' equity minus preferred stock plus deferred tax. The median market value in June 1998 and the $30 \%$ and $70 \%$ quantiles of book-to-market in December 1997 act as breakpoints for portfolio construction. Each firm is labelled by its location relative to these breakpoints: a firm is assigned either small (S) or big (B) in size (market value) and either growth (G), neutral $(\mathrm{N})$, or value $(\mathrm{V})$ in book-to-market. Portfolios pool stocks sharing the same labels and are named accordingly. For example, a firm with lower than median market capitalisation and bookto-market below the $30 \%$ quantile is assigned to the small-growth portfolio (SG). Each June from 1999 to 2006 the stocks are reassigned in the same fashion depending on the book-tomarket of previous December and the current market value.

During July 1998 and June 2000 the return series exhibit high volatility relative to the rest of the sample period. To obtain a clearer picture of the properties of the data generating process in 
recent years the sample is split to obtain two subsamples. The earlier, more volatile period ranges from July 1998 to June 2000 . The stable period begins in July 2000. A difference in dispersion between the periods is formally confirmed by application of two nonparametric tests (Mood-test, Fligner-Killeen-test). These tests are most robust against deviations from the Gaussian distribution (Conover, Johnson, and Johnson, 1981).

In order to study accounting regime effects, the portfolio construction is extended to cover three attributes. As IFRS became mandatory at the beginning of 2005 the sample period is shortened for this analysis. July 2000 is chosen as a starting point for two reasons. First, the IFRS portfolios are too sparsely populated in earlier periods. Second, the higher volatility complicates the analysis of the underlying mechanisms. Data is used up to June 2005, as once IFRS is mandatory the existence of an accounting premium is ruled out by definition. The portfolio design is identical to that of Ernstberger and Vogler (2008). Firms with missing data on monthly returns or negative book equity are excluded. The size attribute ( $\mathrm{S}$ vs. B) is assigned dependent on the market value of a firm in June relative to the median market value in June. Its book-to-market ratio in previous December relative to the $30 \%$ and $70 \%$ quantiles in previous December book-to-market governs the assignment of the book-to-market attribute ( $G$ vs. $N$ vs. $V)$. An accounting attribute is assigned depending on the accounting regime chosen the following December (in the sorting period). "I" indicates IFRS and "G" South African GAAP. Portfolios gather firms sharing all three attributes. This leads to 12 portfolios. Each portfolio is named according to their attributes, for example the portfolio including small firms with low book-to-market and IFRS accounting is termed "SGI". Stocks remain in one portfolio from July to June of the following year.

\section{METHODOLOGY}

\subsection{Value premium}

First, the unconditional distribution of the value premium is considered using the six portfolio sorting. Calculation of monthly average returns generates six monthly return series. These realised returns are treated as proxies for expected returns. This approach has been criticised, as average returns are seen as noisy estimates. However, fewer than half of the companies in the sample actually paid dividends, which rules out estimation techniques based on dividend growth as recently applied in Chen, Petkova, and Zhang (2008). The question of whether to use valueweighted or equally weighted averages is disputed in the literature. Hence, all investigations are carried out using both weighting schemes. In investigations of value-weighted returns, firms are excluded if their market value is missing for one month or more during July and June of the following year. As the results for both schemes are almost identical, the results on equally weighted portfolios are not reported. A portfolio is referred to by its characterising letters, e.g. $\mathrm{SB}$, and its return by adding a time subscript indicating the month of observation, e.g. $S B_{t}, t \in\{1, \ldots, 108\}$.

The value premium is defined as the return difference between value and growth portfolios

$$
V M G_{t}=\left(S V_{t}+B V_{t}\right) / 2-\left(S G_{t}+B G_{t}\right) / 2 \text {. }
$$

This construction results in the value premium factor originally proposed by Fama and French (1992). Findings in Loughran (1997) negate the existence of a value premium for large stocks. 
Following Fama and French (2006), this critique is accounted for by analysing the value premium in two size classes separately. The size specific factors are defined as

$$
\begin{aligned}
V M G S_{t} & =S V_{t}-S G_{t} . \\
V M G B_{t} & =B V_{t}-B G_{t}
\end{aligned} .
$$

Furthermore, the differences in the value premium between the small and large stocks $\left(V M G S_{t}-V M G B_{t}\right)$ are examined.

\subsection{CAPM and multifactor model}

Next, the research examines the conditional distribution of the value premium to investigate whether the value premium is captured by the movement of the market portfolio's excess return as predicted by CAPM. The excess return on a market portfolio is defined as $R M_{t}-R F_{t}$. The market return $\left(R M_{t}\right)$ is calculated as the average return across all stocks. This includes all stocks in the portfolios as well as the stocks with negative book value. A one-month return on a South African Treasury bill with a three-month maturity $\left(R M_{t}\right)$ is subtracted.

Therefore the following equation is estimated by ordinary least square (OLS) regressions:

$R_{t}^{P}-R F_{t}=a+b\left(R M_{t}-R F_{t}\right)+e_{t}$,

with $R_{t}^{P} \in\left\{S V_{t}, S N_{t}, S G_{t}, B V_{t}, B N_{t}, B G_{t}, V M G_{t}\right\}$

Heteroskedasticity is tested using the White test; autocorrelation is checked using the BreuschPagan test. If evidence of heteroskedasticity in the error terms is found, heteroskedasticityconsistent standard errors are used. When robust standard errors are used, the reported $t$-value is marked by a star. Leverage points and outliers are detected using indicators proposed in Belsley, Kuh, and Welsch (1980), and Cook's distance measure (Cook, 1979). An outlier is defined as an observation showing a studentised residual in excess of 3.5 times the series' interquartile range and at least two in absolute value. A leverage point is understood as an observation of which the diagonal entry in the hat matrix (the OLS projection matrix) exceeds 3.5 times the hat values' interquartile range and at least three times the ratio of number of covariates to number of observations. Leverage points or outliers are omitted in the estimation when they result in a change of one standard error in at least one of the slope estimates when omitted or when its Cook's distance exceeds the $50 \%$ quantile of the respective F-distribution.

The often documented inadequacy of CAPM led Fama and French $(1992,1993)$ to develop an alternative model. The CAPM is supplemented by two additional factors meant to indicate distress and hence higher exposure to non-diversifiable risk (Berkowitz \& Qiu, 2001, Fama \& French, 1993). To test whether this model dominates the CAPM in capturing stock return patterns, especially the value premium, the following models are estimated:

$R_{t}^{P}-R F_{t}=a+b\left(R M_{t}-R F_{t}\right)+c S M B_{t}+d V M G_{t}+u_{t}$,

where $R_{t}^{P} \in\left\{S V_{t}, S N_{t}, S G_{t}, B V_{t}, B N_{t}, B G_{t}\right\}$

$S M B_{t}$ is the size premium factor. It is defined as follows:

$S M B_{t}=\left(S V_{t}+S N_{t}+S G_{t}\right) / 3-\left(B V_{t}+B N_{t}+B G_{t}\right) / 3$. 
Estimation techniques are identical to the CAPM case.

\subsection{Accounting premium}

The aforementioned twelve portfolio sort is used for the accounting premium analyses. Valueweighted and equally weighted returns are obtained for the twelve portfolios. First, the unconditional distribution of the accounting premium is examined. The accounting premium is defined as follows:

$$
\begin{aligned}
& G M I_{t}=\left(S G G_{t}+S N G_{t}+S V G_{t}+B G G_{t}+B N G_{t}+B V G_{t}\right) / 6 . \\
& -\left(S G I_{t}+S N I_{t}+S V I_{t}+B G I_{t}+B N I_{t}+B V I_{t}\right) / 6
\end{aligned}
$$

Second, the accounting premium is investigated within the class of small and large stocks, that is

$$
\begin{aligned}
& G M I S_{t}=\left(S G G_{t}+S N G_{t}+S V G_{t}\right) / 3-\left(S G I_{t}+S N I_{t}+S V I_{t}\right) / 3 \\
& G M I B_{t}=\left(B G G_{t}+B N G_{t}+B V G_{t}\right) / 3-\left(B G I_{t}+B N I_{t}+B V I_{t}\right) / 3
\end{aligned}
$$

as well as for growth stocks and value stocks separately, i.e.

$$
\begin{aligned}
& G M I G_{t}=\left(S G G_{t}+B G G_{t}\right) / 2-\left(S G I_{t}+B G I_{t}\right) / 2 \\
& G M I V_{t}=\left(S V G_{t}+B V G_{t}\right) / 2-\left(S V I_{t}+B V I_{t}\right) / 2
\end{aligned}
$$

The differences in the accounting premium between size classes $\left(G M I S_{t}-G M I B_{t}\right)$ is examined as well as the accounting premium between growth and value stocks $\left(G M I V_{t}-G M I G_{t}\right)$.

\subsection{The value premium and the accounting premium as risk factors}

Self-selection might occur in the analyses because firms with lower risk loadings might use IFRS to try to signal this to potential investors (Hail, 2002). In this case IFRS adoption and returns will show negative correlation. However, this will not be linked to the accounting regime. Finding the accounting premium within different portfolios sorted by risk characteristics such as size and book-to-market is an indication of accounting being a risk factor on its own. In addition, selfselection problems are addressed using regression analysis to control for known risk-mimicking portfolios, i.e. SMB and VMG (Berk, 1995).

For this analysis the size premium factor and the value premium have to be adapted to the new portfolio structure:

$$
\begin{aligned}
& S M B_{t}=\left(S V I_{t}+S V G_{t}+S N I_{t}+S N G_{t}+S G I_{t}+S G G_{t}\right) / 6, \\
& -\left(B V I_{t}+B V G_{t}+B N I_{t}+B N G_{t}+B G I_{t}+B G G_{t}\right) / 6 \\
& V M G_{t}=\left(S V I_{t}+S V G_{t}+B V I_{t}+B V G_{t}\right) / 4+\left(S G I_{t}+S G G_{t}+B G I_{t}+B G G_{t}\right) / 4
\end{aligned}
$$

The Fama and French multifactor model is estimated for the twelve portfolios using the shorter time frame. This amounts to estimation of the following equations

$$
\begin{aligned}
& R_{t}^{P}-R F_{t}=a+b\left(R M_{t}-R F_{t}\right)+c S M B_{t}+d V M G_{t}+\varepsilon_{t}, \\
& R_{t}^{P} \in\left\{S V_{t}, S N_{t}, S G_{t}, B V_{t}, B N_{t}, B G_{t}, V M G_{t}\right\}
\end{aligned}
$$

To test if the accounting premium reflects a risk factor, the following equations proposed by 
Ernstberger and Vogler (2008) are estimated:

$$
\begin{aligned}
& R_{t}^{P}-R F_{t}=a+b\left(R M_{t}-R F_{t}\right)+c S M B_{t}+d V M G_{t}+e G M I_{t}+v_{t}, \\
& R_{t}^{P} \in\left\{S V_{t}, S N_{t}, S G_{t}, B V_{t}, B N_{t}, B G_{t}\right\}
\end{aligned}
$$

The calculation of the market portfolio's excess return and the estimation is the same as for the CAPM.

\section{RESULTS}

\subsection{Value premium}

The summary statistics for the value premium are shown in TABLE $\mathbf{l}$.

\begin{tabular}{|c|c|c|c|c|}
\hline \multicolumn{5}{|c|}{ Value Premium } \\
\hline $07 / 1998-06 / 2007$ & $V M G$ & VMGS & $V M G B$ & $V M G S-B$ \\
\hline \multirow[t]{2}{*}{ Mean } & 1.62 & 2.20 & 1.04 & 1.16 \\
\hline & $(2.37)$ & $(2.83)$ & $(1.33)$ & $(0.56)$ \\
\hline \multirow[t]{2}{*}{ Median } & 2.08 & 2.29 & 1.71 & 0.58 \\
\hline & $(<0.01)$ & $(<0.01)$ & $(0.03)$ & $(0.12)$ \\
\hline $07 / 2000-06 / 2007$ & $V M G$ & $V M G S$ & $V M G B$ & $V M G S-B$ \\
\hline \multirow[t]{2}{*}{ Mean } & 1.92 & 1.95 & 1.89 & 0.05 \\
\hline & $(3.80)$ & $(3.45)$ & $(2.67)$ & $(0.07)$ \\
\hline \multirow[t]{2}{*}{ Median } & 2.08 & 1.85 & 1.90 & -0.05 \\
\hline & $(<0.01)$ & $(<0.04)$ & $(<0.01)$ & $(0.62)$ \\
\hline
\end{tabular}

TABLE 1: Summary statistics for the value premium

Source: Authors

Six portfolios are formed on size (small (S) and big (B)) and the book-to-market ratio (growth $(G)$, neutral $(N)$, and value $(V)$ ). These portfolios are realigned annually. Value-weighted return series are calculated for each portfolio. VMG (value-minus-growth) represents the difference in returns between value and growth stocks; VMGS and VMGB embody the value premium for small and big firms. VMGS-B gives the difference between the value premiums in both size classes. Distributions are investigated using three time frames: the full sample, the first two years which exhibit excessive volatility (not tabulated), and the rest of the sample. TABLE 1 shows means and $t$-ratios for the mean in parenthesis for the value premium series for the full sample period and the second subsample period. In addition, the median and underneath the $p$-value of a Wilcoxon signed-rank test with the null of a non positive median in parenthesis are reported for the series during both time periods. The mean and the median are given as percentage points and are printed in boldface, if they are significant at a $5 \%$ level.

In the full sample period (top half of TABLE 1) estimates for the mean ( $1.62 \%, 2.20 \%$, and 
$1.04 \%$ ) and the median $(2.08 \%, 2.29 \%$, and $1.71 \%$ ) are positive among all stocks - small and large stocks. Statistical significance is indicated by both $t$-statistics and the Wilcoxon test in the pooled sample as well as for small stocks. For big stocks the $t$-test is inconclusive. Nevertheless, the Wilcoxon test shows significance. Furthermore, the value premium difference between small and large stocks is insignificant. Estimates of the value premium factor's distribution illustrated in FIGURE $\mathbf{l}$ illustrate the positive location among all stocks, as well as among small and big stocks.

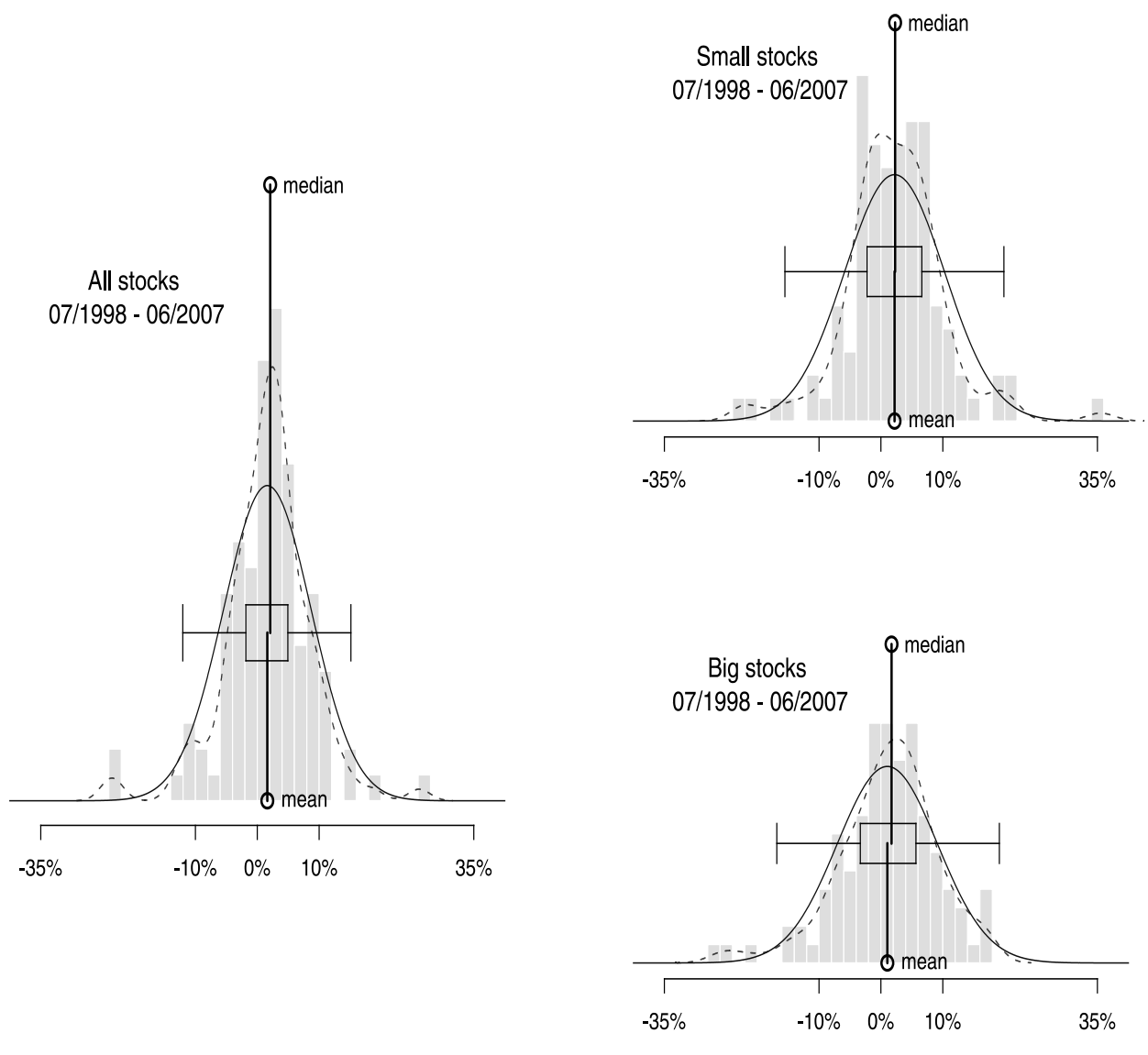

FIGURE 1: Distribution of the Value Premium among all firms and among small and big firms

\section{Source: Authors}

FIGURE 1 shows the distribution of the value premium during the full sampling period. The panel on the left side shows the distribution among all stocks. On the right side, the top panel shows the distribution among big stocks (bottom) and among small stocks (top). The solid line is a parametric density estimate based on a Gaussian distribution; the dashed line is a nonparametric density estimate. The latter indicates deviations from normality. The solid line starting from below is located at the mean; the solid line starting from above is located at the median. In addition, a box plot summarises the distributions.

To obtain further insight, the possibility of structural breaks is considered. FIGURE 2 shows that 
the volatility has decreased tremendously up to mid-2000. Test of change in the variance rejects a constant dispersion at a $1 \%$ confidence level (in the case of VMGB a $2 \%$ level is needed).

\section{Small stocks}
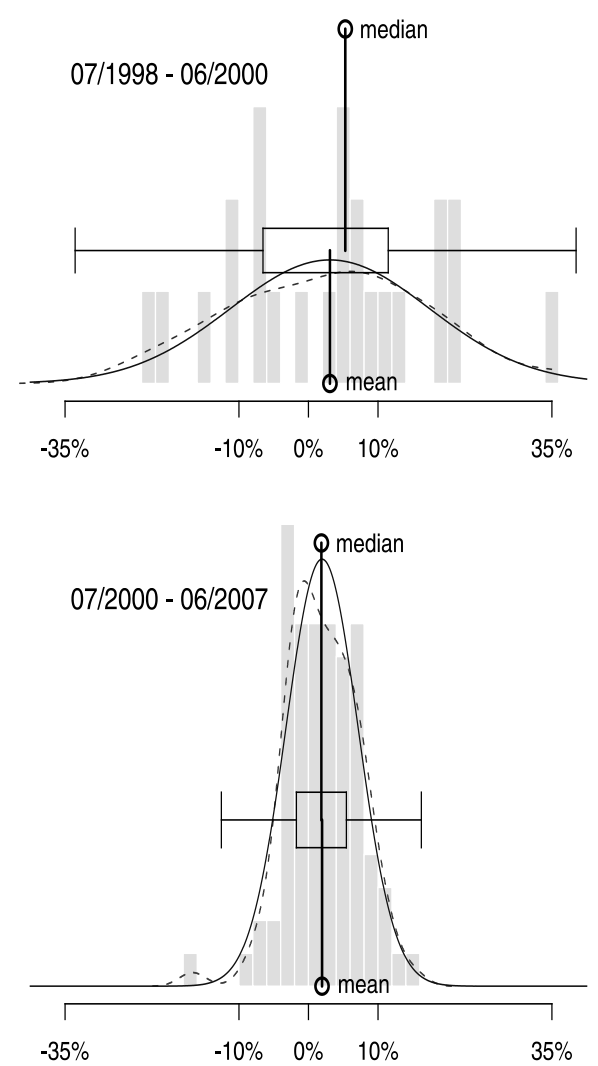

Big stocks
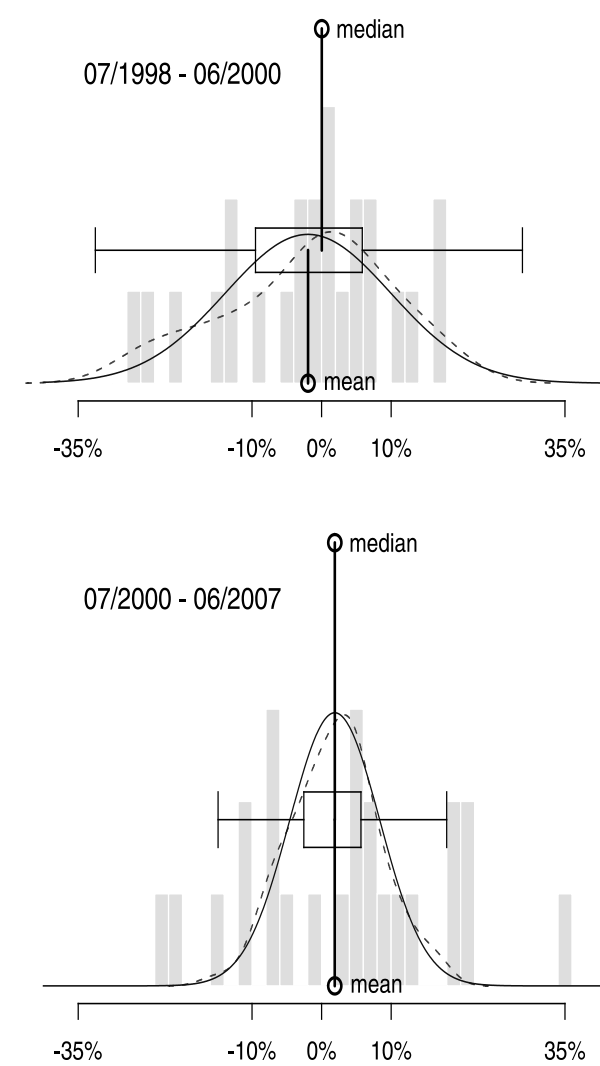

FIGURE 2: Distribution of the Value Premium among small and big firms during the two subperiods

\section{Source: Authors}

The four panels of FIGURE 2 show the distribution of the value premium among small stocks (left) and among large stocks (right). The two upper panels show the distributions in the earlier sample period. The two panels below show the distributions in the second period. The solid line is a parametric density estimate based on a Gaussian distribution; the dashed line is a nonparametric density estimate. The latter indicates deviations from normality. The solid line starting from below is located at the mean; the solid line starting from above is located at the median. In addition, a box plot summarises the distributions.

The estimates for the more volatile period June 1998 - July 2000 (not tabulated) are imprecise and allow little inference. The bottom part of TABLE 1 reports estimates and test statistics for the period from July 2000 to June 2007 . For all stocks - small stocks and large stocks - the mean estimates $(1.92 \%, 1.95 \%$, and $1.89 \%$ ) and median estimates $(2.08 \%, 1.85 \%$, and $1.90 \%$ ) show a 
value premium. $t$-statistics and the Wilcoxon test show that these are significant findings. Thus, more recently the value premium for large stocks is clearly present. Differences in the value premium between small and large stocks cannot be found. This is robust evidence for the existence of a value premium for both stock sizes in the post-2000 period.

These findings bear resemblance to those of Fama and French (2006) for the US market. Fama and French investigated the value-weighted return series for stock portfolios ranging from July 1926 to June 1963. The portfolio design is identical to the one in this study. They assessed the value premium for the full sample as well as for two subsamples ranging from July 1926 to June 1963 and from July 1963 to June 2004 . As the present research is conducted on very recent data, using results on the latter as a benchmark is more appropriate. Although being different in quantitative terms - the US portfolio returns' means range from $0.62 \%$ to $1.22 \%$, while here a range of $1.04 \%$ to $2.20 \%$ is observed - the qualitative implications coincide: Fama and French find a value premium significantly different from zero (with $t$-ratios of 3.34 and 3.97 ) when looking at the overall level and when looking specifically at small firms. Their evidence for a value premium among big firms, a $t$-ratio of 1.87 , is rather mixed. Sorting by the earnings-price ratio instead of book-to-market, however, clearly indicates its existence. Also when looking at a richer history of the full sample period, they find a $t$-ratio of 2.23 .

\subsection{CAPM and multifactor model}

Next, the conditional distribution of the value premium is investigated to see whether the premium is captured by the movements of the market as predicted by the CAPM. The previous results have shown the later subsample (July 2000 - June 2007) to exhibit a different distribution from the earlier subsample (July 1998 - June 2000). The more recent period gives a clearer picture on the value premium and exhibits less volatility. The investigation is confined to this subsample. Results are given in TABLE 2.

TABLE 2: CAPM and Multifactor model regression results, July 2000 to June 2007 (84 month)

\begin{tabular}{|c|c|c|c|c|c|c|c|}
\hline & \multicolumn{7}{|c|}{ CAPM } \\
\hline & $V M G$ & $S G$ & $S N$ & SV & $B G$ & $B N$ & $B V$ \\
\hline \multirow[t]{2}{*}{ A } & 0.044 & 0.013 & 0.026 & 0.035 & -0.011 & 0.01 & 0.015 \\
\hline & (4.14) & (2.55) & (5.82) & $\left(8.56^{\star}\right)$ & $(-3.70)$ & $(2.56)$ & $(2.85)$ \\
\hline \multirow[t]{3}{*}{ b } & -0.318 & 0.571 & 0.425 & 0.458 & 1.166 & 0.783 & 0.784 \\
\hline & $(-1.81)$ & (6.88) & $(5.82)$ & $\left(5.05^{\star}\right)$ & $(24.25)$ & $(14.14)$ & $(8.94)$ \\
\hline & \multicolumn{7}{|c|}{ Multifactor model } \\
\hline \multirow[t]{2}{*}{$a$} & & -0.001 & 0.001 & -0.002 & -0.003 & 0.002 & -0.002 \\
\hline & & $(-0.19)$ & $(0.08)$ & $(-0.74)$ & $\left(-0.97^{\star}\right)$ & $(0.45)$ & $(-0.30)$ \\
\hline \multirow[t]{2}{*}{$d$} & & -.0238 & 0.300 & 0.647 & -0.373 & 0.339 & 0.743 \\
\hline & & $(-3.21)$ & (3.97) & $(12.55)$ & $\left(-7.25^{\star}\right)$ & $(5.11)$ & $(8.51)$ \\
\hline obs. & 84 & 84 & 84 & 84 & 84 & 84 & 84 \\
\hline
\end{tabular}

Source: Authors 
Six portfolios are formed on size (small (S) and big (B)) and book-to-market (growth (G), neutral $(\mathrm{N})$, and value $(\mathrm{V})$ ). The CAPM and a multifactor model are estimated for all six portfolios. In addition, the CAPM is estimated separately for the value premium. The top part of the table provides the intercept and beta estimates for the CAPM and $t$-ratios in parenthesis. The bottom part gives the intercept estimates as well as the slope estimates of the value premium for multifactor model, $t$-ratios and the number of observations used. $T$-ratios are marked with a star, if the $t$-ratio is calculated using heteroskedasticity robust standard errors. Coefficients are printed in boldface, if they are significantly different from zero at a $5 \%$ level

The theory surrounding the CAPM is free of an intercept. If the intercept is found to be significantly different from zero, this amounts to a rejection of the theory. The top part of TABLE 2 shows that the CAPM is rejected for all portfolios. Moreover, the value premium is not captured: both value portfolios (SV and BV) exhibit lower betas ( 0.458 and 0.784 ) than the respective growth portfolios $(0.571$ and 1.166$)$. As a result, the value premium shows a negative beta with a value of -0.318 . These findings are in line with the results for the US market of Fama and French $(1993,2006)$.

Results in the bottom part of TABLE 2 suggest that inclusion of additional risk factors indeed mitigates these problems. Once the additional factors are controlled for, all intercepts become insignificant. The multifactor model is more powerful in explaining the cross-section of returns. The slopes in the multifactor model represent risk factor loadings. Evidence for a value premium was found earlier. Stocks exhibiting a higher risk load should on average have larger returns. The results in TABLE 2 show that the book-to-market loadings are 0.6468 for value stocks versus -0.2377 for growth stocks within the class of small stocks and 0.7427 versus -0.3726 when looking at large stocks. The factor loadings are significantly different from zero without exception. Therefore, the multifactor model does better in explaining the value premium. These findings are very similar to those of Fama and French (1993) for the US market.

\subsection{Accounting premium}

The summary statistics are found in TABLE 3 and illustrated in the left panel of FIGURE 3.

TABLE 3: Summary statistics for the accounting premium, July 2000 to June 2005 (60 month)

\begin{tabular}{lccccccc}
\hline \multicolumn{7}{c}{ Accounting premium } \\
& GMI & GMIV & GMIG & GMIV-G & GMIS & GMIB & GMIS-B \\
\hline Mean & $\mathbf{1 . 8 3}$ & 1.97 & 0.43 & 1.54 & $\mathbf{3 . 2 4}$ & $\mathbf{- 0 . 1 9}$ & $\mathbf{3 . 4 3}$ \\
& $(3.25)$ & $(1.65)$ & $(0.55)$ & $(1.12)$ & $(6.15)$ & $(-0.19)$ & $(2.1534)$ \\
\multirow{4}{*}{ Median } & $\mathbf{1 . 7 8}$ & $\mathbf{1 . 6 7}$ & 0.85 & 0.82 & $\mathbf{3 . 5 7}$ & 0.90 & $\mathbf{2 . 6 7}$ \\
& $(<0.01)$ & $(0.02)$ & $(0.21)$ & $(0.11)$ & $(<0.01)$ & $(0.44)$ & $(0.02)$ \\
\hline
\end{tabular}

Source: Authors

Twelve portfolios are formed on size (small (S) and big(B)), book-to-market (growth (G), neutral $(\mathrm{N})$, value $(\mathrm{V})$ ), and accounting regime used (IFRS (I) and SA GAAP (G)). Portfolios are realigned each year. For each portfolio a value-weighted return series is calculated. GMI embodies the difference in the returns between SA GAAP stocks and the IFRS stocks. GMIV captures this difference for value stocks only; GMIG does the same for growth stocks. GMIS and GMIG give this difference within the class of small stocks and big stocks, respectively. GMIV-G is 
the difference in the accounting premium series between value stocks and growth stocks. GMISB similarly captures the difference in the accounting premium between small and big stocks. The table supplies means, $t$-ratios for the means in parenthesis, as well as the median and underneath a $p$-value of a Wilcoxon signed rank test against the null of a non-positive location in parenthesis. Mean and median are given in percentage points and are printed in boldface, if they are significantly different from zero at a $5 \%$ level.

The estimated mean is $1.83 \%$ among all stocks. The estimated density of the accounting premium for value-weighted portfolio returns shows the strictly positive location. The mean estimate is 3.25 standard errors from zero. The Wilcoxon signed-rank test rejects the null of a non-positive median and supports the conclusion of the existence of an accounting premium.
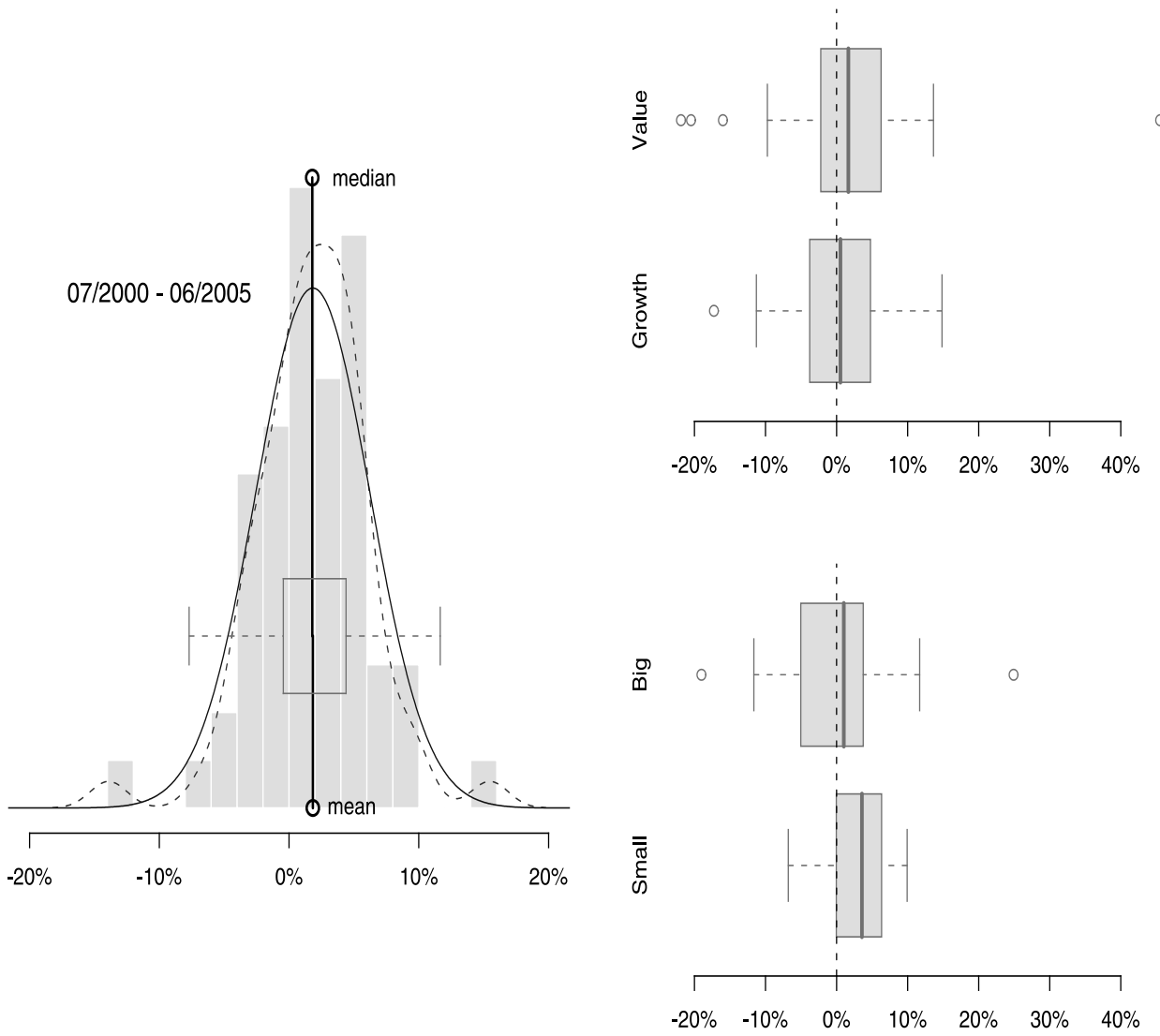

FIGURE 3: Distribution of the Accounting Premium among all firms, within different size class, for value stocks and growth stocks

Source: Authors

The left panel in FIGURE 3 shows the distribution of the accounting premium factor among all stocks. The two panels on the right side show box plots summarising the distributions within different size and book-to-market classes. In the left panel the solid line is a parametric density estimate based on a Gaussian distribution; the dashed line is a nonparametric density estimate. The latter indicates deviations from normality. The solid line starting from below is located at the mean; the solid line starting from above is located at the median. In addition, a box plot 
summarises the distributions.

For the class of value stocks the findings are similar: an accounting premium of slightly less than $2 \%$ exists. However, for growth stocks neither the $t$-ratio nor the Wilcoxon test supports its existence. Comparing the accounting premium for value and growth stocks, neither the Wilcoxon nor the $t$-ratio indicates a difference. The accounting premium seems to be present in the class of small stocks. Large stocks do not exhibit this pattern. Here both the $t$-ratio and the Wilcoxon test indicate a different premium. These findings are supported by the visual impression of the two right panels in FIGURE 3. The value premium clearly differs between size classes; comparing the value stocks to growth stocks yields less clear results. Nevertheless, the evidence for the accounting premium in both classes separately is unambiguous.

Other risk factors are controlled for by estimation of an enhanced factor model. Data limitations are an issue: estimation for the SGI portfolio is not possible, since SGI features a zero population up to June 2005. When rather sparsely populated portfolios are used, controlling outliers is important. Thus, the procedure described above is used. TABLE 4 reports the estimation results on both the multifactor model and the enhanced multifactor model.

TABLE 4: Estimation results for the multifactor model, July 2000 to June 2005 (60 month)

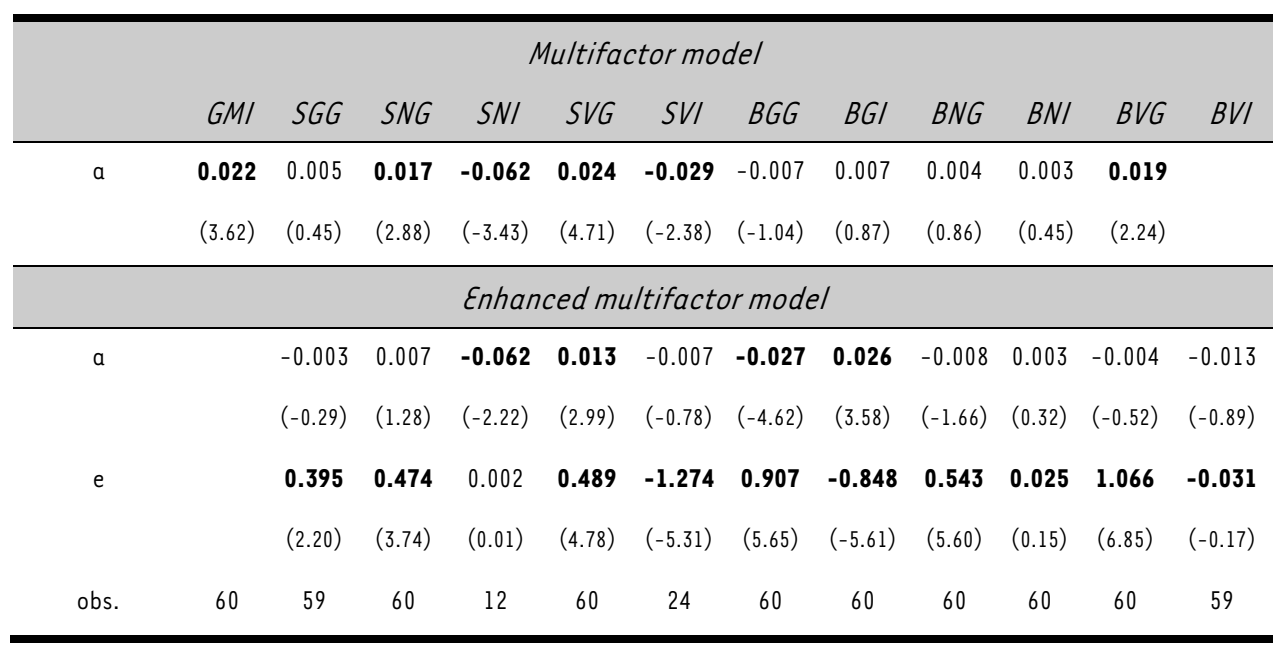

Source: Authors

Twelve portfolios are formed on size (small (S) and big (B)), book-to-market (growth (G), neutral $(\mathrm{N})$, value $(\mathrm{V})$ ), and accounting regime used (IFRS (I) and SA GAAP (G)). Portfolios are realigned annually. For each portfolio a value-weighted return series is calculated. The Fama and French multifactor model is estimated both for all twelve portfolios and the accounting premium. The upper part of the table supplies the intercept estimates of all series and t-ratios in parenthesis. The enhanced multifactor model is also estimated for all twelve series. The bottom part of the table gives intercept estimates as well as slope estimates for the accounting premium. The SGI portfolio is omitted due to data unavailability. All coefficients significant at a $5 \%$ level are printed in boldface.

The intercept of the regression of the accounting premium on the other risk factors is significantly different from zero. Hence, other risk factors do not fully explain this premium. The loading on accounting risk is found to be higher for firms using SA GAAP. Most of the loadings are 
significantly different from zero. The enhanced multifactor model produces less significant intercepts and hence outperforms the classical multifactor model in explaining the crosssection of stock returns. Hence, the results support the view that the accounting standard in use is a priced risk factor.

\section{CONCLUSION}

The existence of two return premiums, the value premium and the accounting premium, was investigated in the South African stock market. It was found that a value premium exists if stock return expectations increase with the ratio of book value of equity to market value of equity. An accounting premium exists if investors award a firm's voluntary compliance to IFRS with a lower expected return. The sample of this study consists of 159 stocks listed at the JSE Limited from July 1998 to June 2007 . A positive value premium of about $1.5 \%$ to $2 \%$ was identified over the full period, taking all stocks into consideration. This also holds within the class of small stocks. Taking into account the high volatility prior to 2000 , the results also extend to the class of big stocks. The CAPM fails to explain the cross-section and more specifically the value premium; a multifactor model dominates the CAPM. Evidence for the existence of an accounting premium between $1.5 \%$ and $2 \%$ was found among all stocks. A closer investigation showed that it is limited to the class of value stocks and small stocks. Furthermore, it was shown that the accounting premium is robust against possible self-selection. The findings on the value premium are qualitatively identical to recent evidence for the US market provided by Fama and French (2006). Further research opportunities include a closer investigation of the existence and the properties of both premiums in classes formed on different risk-related properties. Significantly, this would necessitate a richer data set.

\section{Acknowledgement}

A previous version of this paper was presented at the Value 2008 Conference held at Sun City, South Africa, in May 2008. We are particularly grateful to Paul Snyman and conference participants for their comments. We also like to thank the two anonymous referees for their suggestions and the helpful comments.

\section{REFERENCES}

African Securities Exchanges Association. (2008). Annual Statistics. Available from: http://www.africansea.org/ASEA/Members_Annual_Statistics.aspx. (Accessed 01 July 2008).

Belsley, D. A., Kuh, E. \& Welsch, R. E. (1980). Regression Diagnostics. New York: Wiley.

Berk, J. (1995). A critique of size-related anomalies, Review of Financial Studies, 8(2), pp. 275-286.

Berkowitz, M. K. \& Qiu, J. (2001). Common Risk Factors in Explaining Canadian Equity Returns. Toronto: University of Toronto.

Che, L., Petkova, R. \& Zhang, L. (2008). The expected value premium, Journal of Financial Economics, 87(2), pp. 269-280.

Conover, W. J., Johnson, M. E. \& Johnson M. M. (1981). A comparative study of tests for homogeneity of variances, with applications to the outer continental shelf bidding data, Technometrics, 23(4), pp. 351-361. 
Cook, R. D. (1979). Influential observations in linear regression, Journal of the American Statistical Association, 74(365), pp. 169-174.

Ernstberger, J. \& Vogler, 0. (forthcoming). Analyzing the German Accounting Triad- 'Accounting Premium' for IAS/IFRS and US GAAP vis-à-vis German GAAP? The International Journal of Accounting.

Fama, દ. F. \& French, K. R. (1992). The Cross-Section of Expected Stock Returns, Journal of Finance, $47(2)$, pp. $427-465$.

Fama, દ. F. \& French, K. R. (1993). Common risk factors in the returns on stocks and bonds, Journal of Financial Economics, 33(1), pp. 3-56.

Fama, E. F. \& French, K. R. (2006). The Value Premium and the CAPM, The Journal of Finance, 61(1), pp. 2163-2185.

Hail, L. (2002). The impact of voluntary corporate disclosures on the ex-ante cost of capital for Swiss firms, The European Accounting Review, 11(4), pp. 741-773.

JSE Limited (2004). Ful/ Compliance with Internationa/ Financial Reporting Standards from 1 January 2005. Available from: http://www.jse.co.za/docs/listings/ifrs.pdf. (Accessed 01 July 2008).

JSE Limited (2008). History/Residence. Available from: http://www.jse.co.za/history_residence.jsp. (Accessed 01 July 2008).

Loughran, T. (1997). Book-to-market across firm size, exchange, and seasonality, Journal of Finance and Quantitative Analysis, 32(3), pp. 249-268.

Page, M. \& Palmer, F. (1993). The relationship between excess returns, firm size and earnings on the Johannesburg Stock Exchange, South African Journal of Business Management, 22(9), pp. 63-73.

Van Rensburg, P. (2001). A decomposition of style based risk on the JSE, Investment Analysts Journal, 54 , pp. $45-60$.

Van Rensburg, P. \& Roberts, M. (2003). Style Variables and the Cross-Section of JSE Returns. Investment Analysis Journal, 57, pp. 7-15.

World Federation of Exchanges (2008). Statistics on domestic market capitalization. Available from: http://www.world-exchanges.org/WFE/home.asp?menu=426\&document=4770. (Accessed 01 July 2008). 
Ernstberger, Heinze \& Vogler 